\title{
Campamento Unidad Popular (1970-1973): movimiento de pobladores y poder popular en la zona sur-oriente de Santiago
}

\author{
Unidad Popular squatter settlement (1970-1973): squatter's movement and \\ people's power in the south-east zone of Santiago
}

\author{
Ignacio Rojas Dunlop*
}

\begin{abstract}
Resumen: Utilizando fuentes primarias y secundarias, la presente investigación busca caracterizar al campamento Unidad Popular, con el fin de sistematizar la información disponible sobre él y cuestionar la creencia de que solo en campamentos asociados a la izquierda revolucionaria se desarrollaron formas embrionarias de poder popular, antes y durante el gobierno de la Unidad Popular, así como reconocer el aporte de la izquierda tradicional, sobre todo el Partido Comunista, en el desarrollo del movimiento de pobladores.
\end{abstract}

alabras clave: movimiento social, movimiento de pobladores, campamentos, poder popular, toma de terrenos.

Abstract: Using primary and secondary sources, the present investigation tries to characterize the Unidad Popular squatter settlement, with the purpose of systematize the available information about it and question the belief that only in squatter settlements associated to the revolutionary left embryonic forms of people's power were developed, before and during the Unidad Popular government, as well as recognize the contribution of traditional left, especially the Communist Party, to the development of the squatter's movement.

Keywords: social movement, squatter's movement, squatter's settlement, people's power, land seizures.

Recibido: 21 marzo 2018 Aceptado: 6 junio 2018

\footnotetext{
* Chileno. Antropólogo Social, Universidad de Chile. Este artículo es una versión revisada de tesina presentada al Diplomado en Teoría, Metodología y Enseñanza de la Historia Reciente del Instituto de Estudios Avanzados (Universidad de Santiago de Chile), a fines del año 2017. Correo electrónico: irojasdunlop@gmail.com
} 


\section{Introducción}

La presente investigación indaga en la historia y las características que tuvo un extenso campamento que existió en la zona sur-oriente de Santiago (en el límite norte de la comuna de La Florida, específicamente): el campamento Unidad Popular, formado a partir de una toma de terrenos realizada el 11 de enero de 1970, y a partir del cual se crearían las actuales poblaciones Los Copihues y Las Araucarias.

Al comenzar a estudiar la historia de dicho campamento llamó la atención la falta de información disponible sobre él, en general, y una sistematización de la poca existente, en particular. Esto a pesar de que fue resultado de la primera toma de terrenos del políticamente clave año 1970, así como uno de los más poblados de la historia, llegando a albergar a unas 2.500 familias, según estimación del equipo de estudios poblacionales del Centro Interdisciplinario de Desarrollo Urbano (CIDU) de la Pontificia Universidad Católica de Chile ${ }^{1}$. Lo habrían habitado, por lo tanto, unas 12.500 personas, cifra obtenida al multiplicar el número de familias por 5, promedio de individuos por familia en la época "según los resultados de los censos en Chile",

Respecto a la poca información disponible sobre este campamento, era notoria sobre todo si se le comparaba con otro con el que, coincidentemente, colindaba hacia el oriente: el Nueva La Habana (conformado por 1.600 familias, según Equipo de Estudios Poblacionales del CIDU), del cual existen múltiples investigaciones sociológicas e históricas, tanto centradas específicamente en él ${ }^{3}$, como poniéndolo como ejemplo paradigmático de la organización alcanzada en campamentos durante la Unidad Popular ${ }^{4}$.

Esta notable diferencia sería producto, se ha sostenido, de que el campamento Nueva La Habana fue uno cualitativamente distinto a los demás que existieron en la época, ya que allí se habrían dado formas organizativas y de movilización novedosas con respecto a las desarrolladas dentro del movimiento poblacional hasta entonces, caracterizadas por plantearse conscientemente como un poder popular autónomo respecto al poder estatal, a la manera de una democracia directa, y por articular "las luchas del movimiento poblacional con las del resto del movimiento social, rompiéndose la lógica atomizante que había predominado" 5 en un

\footnotetext{
1 Equipo de Estudios Poblacionales CIDU, "Reivindicación urbana y lucha política: los campamentos de pobladores en Santiago de Chile", EURE, N 6, vol. 2, Santiago, 1972, 55-82.

2 Boris Cofré, "El movimiento de pobladores en el Gran Santiago: las tomas de sitios y organizaciones en los campamentos. 1970-1973", Tiempo Histórico, N² 2, Santiago, 2011, 138.

3 Por ejemplo, Boris Cofré, Campamento Nueva La Habana, el Mir y el Movimiento de Pobladores, 1970-1973, Concepción, Escaparate, 2007, 271 p., Sebastián Leiva, "De la toma de terrenos a la toma del poder": el campamento "Nueva La Habana" y una nueva óptica para la movilización poblacional”, Revista de Historia Social y de las Mentalidades, $\mathrm{N}^{\circ}$ 6, Santiago, 2002, 109-123, Jorge Fiori, "Campamento Nueva La Habana: estudio de una experiencia de autoadministración de justicia”, EURE, $N^{\circ} 72$, vol. 24, Santiago, 1973, 71-84, entre otras.

4 Por ejemplo, Mario Garcés, "Los años de la Unidad Popular: cuando los pobladores recreaban las ciudades chilenas", en Julio Pinto (ed.), Fiesta y drama. Nuevas historias de la Unidad Popular, Santiago, LOM, 2014, 51-73, Mario Garcés, "Construyendo "poblaciones", en Julio Pinto (ed.), Cuando hicimos historia. La experiencia de la Unidad Popular, Santiago, LOM, 2005, 57-79, Ernesto Pastrana y Mónica Threlfall, Pan, techo y poder: el movimiento de pobladores en Chile (1970-1973), 1974, Disponible en internet:

http://www.blest.eu/biblio/pastrana/index.html

${ }^{5}$ Leiva, 2002, op. cit., 110.
} 
momento anterior, en que el movimiento de pobladores había estado ligado políticamente más que nada a los partidos democratacristiano (PDC) y comunista (PC). Este cambio se habría producido por la introducción del Movimiento de Izquierda Revolucionaria (MIR) y su política revolucionaria en el movimiento de pobladores hacia 1970, especialmente a partir de su dirección e influencia en el campamento Nueva La Habana, el cual se formó el primero de noviembre de ese año, tras la relocalización de tres campamentos asociados al MIR: Ranquil, Magaly Honorato y Elmo Catalán.

Habiéndose constatado lo anterior, surgió la interrogante respecto a la influencia que en la conformación y desarrollo del campamento Unidad Popular tuvo algún partido o corriente política, hallándose que habría estado asociado al $\mathrm{PC}^{6}$, o bien a una alianza entre "los partidos obreros, PC y PS"7 (Partido Socialista). Por tanto, este campamento habría sido uno representativo de la estrategia con que los partidos de izquierda tradicionales se relacionaron con el movimiento de pobladores, a partir de la cual no se habrían desarrollado mayormente formas organizativas y de movilización autónomas, a la manera de un poder popular embrionario, al menos, que conectara la lucha poblacional con una más global durante el gobierno de la Unidad Popular.

Sin embargo, no existía una sistematización de la información disponible sobre este campamento que permitiera, con certeza, confirmar o rechazar la conexión anteriormente expuesta. Justamente lo que se pretende realizar con esta investigación es eso, planteando dicha problemática como interrogante de la siguiente manera: ¿cómo se insertó, si es que lo hizo, el campamento Unidad Popular en el movimiento de pobladores que se desarrolló entre 1970 y 1973? Y, de hacerlo, ¿se desplegó a partir de él un poder popular autónomo, tal como algunos autores sostienen que se desplegó en otros campamentos organizados en esos años como, por ejemplo, y sobre todo, el campamento Nueva La Habana, con el que colindaba?

La hipótesis que se sostiene es que, efectivamente, el campamento Unidad Popular se insertó en el movimiento de pobladores desarrollado en esos años, y que en su interior sí se dieron formas organizativas y de lucha que podrían considerarse similares a otras desarrolladas en esa época, y que han sido consideradas como manifestaciones de un poder popular embrionario surgido a partir de la movilización llevada a cabo por los pobladores. Dicho desarrollo no sería, por tanto, una "facultad" exclusiva de los campamentos conducidos por el MIR a partir de 1970, como ha sido sostenido, como veremos, desde la década del 70, sino que también existió dentro de campamentos asociados a los partidos de izquierda tradicionales (específicamente, en este caso, el PC).

Se trata, por tanto, de una investigación de carácter exploratorio, dada la escasez de conocimientos específicos y sistemáticos existentes sobre el campamento Unidad Popular y su relación con la coyuntura política de la época. A partir de su estudio se pondrán en cuestión las complejas relaciones que en ese entonces existían entre lo social y lo político, intentando ir más allá de una nostálgica historia local, para pasar al ámbito de la Microhistoria, la cual "no

${ }^{6}$ Cofré, 2011, op. cit., 144.

${ }^{7}$ Manuel Castells, "Movimiento de pobladores y lucha de clases en Chile", EURE, N 7, vol. 7, Santiago, 1973, 25. 
renuncia a los problemas generales, sino que los trata vistos a propósito de un particular" ${ }^{8}$ (el campamento Unidad Popular, en este caso). Esto entendiendo

La historia como el relato de la acción humana, las elecciones humanas, de la gente que trata de resolver sus relaciones sociales cambiantes $-\mathrm{y}$ muchas veces desiguales- en medio de sus circunstancias cambiantes y también, muchas veces, desiguales. Con esta comprensión del pasado podemos ser más capaces de enfrentarnos, inteligente y humanamente, con valor y humildad, a los problemas muy reales que nos confrontan en el presente?

Así, el pensar el movimiento de pobladores y el poder popular surgido a partir de él a principios de la década del 70 puede señalar caminos posibles de seguir respecto a las relaciones que actualmente establecen la institucionalidad política y grupos de pobladores que, tal como los que formaron los campamentos de esos años, agobiados por la precariedad de las condiciones materiales en las que habitan buscan maneras de darse un lugar de vida digno en la ciudad.

En cuanto a la metodología utilizada, puede señalarse que las características del campamento Unidad Popular fueron identificadas a partir de la revisión de prensa de la época, así como de bibliografía existente que se refería a él. Se trata, por lo tanto, de una investigación bibliográfica que utiliza fuentes tanto primarias como secundarias.

La utilización de fuentes orales no fue considerada para la realización del estudio debido, en primer lugar, a falta de tiempo para su correcta implementación y análisis. Las características del proceso en que se produjo (redacción de una tesina en un tiempo limitado) impedían llevar a cabo una investigación que utilizara tanto fuentes bibliográficas como orales de manera acuciosa y acabada, sin correr el riesgo de desatender la revisión de unas por sobre otras. Es por eso que, con la intención de sentar una base sólida de conocimiento, se tomó la decisión de trabajar a partir de todas las fuentes bibliográficas y documentales que fueran posibles de encontrar, sobre la cual sería posible seguir indagando en la historia de este campamento, pero sumando las memorias de quienes le dieron vida. Así, se prefirió primero resumir, organizar, sistematizar y analizar la información actualmente existente sobre el campamento, para posteriormente generar nuevos datos a partir de fuentes orales, los cuales sin duda permitirán comprender más cabalmente su devenir.

La falta de fuentes orales en la presente investigación se intentó, en algún grado al menos, cubrir a partir de la revisión de una fuente que se vale principalmente de ellas, de invaluable valor para el conocimiento sobre el campamento Unidad Popular: el primer capítulo del libro "Historias Locales I", editado por Hanny Suckel, denominado "Campamento Unidad Popular (Villa Los Copihues)", realizado por Andrés Moreno. Este texto fue desarrollado en 1989, en el marco de la Tercera Escuela de Planificación Vecinal del Equipo Urbano de Jundep (ONG Juventudes para el Desarrollo y la Producción), de la cual el autor era alumno, como dirigente joven.

\footnotetext{
8 Pablo Aravena Núñez, "Patrimonio, historiografía y memoria social: "presentismo radical" y abdicación de la operación histórica”, Diálogo Andino, N 45, Arica, 2014, 80.

${ }^{9}$ Linda Shopes, 1993, en Ibid., 81.
} 
Con respecto a la organización del trabajo, este comienza con la exposición y debate de los conceptos fundamentales utilizados a lo largo de la investigación: movimiento de pobladores y poder popular. Luego se presentan, analizan e interpretan los resultados de la investigación a la luz de las conceptualizaciones antes discutidas, con el fin de dar respuesta a la pregunta de investigación. Finalmente se señalan las principales conclusiones a las que se llegó tras el trabajo investigativo e interpretativo, sintetizando lo realizado y ofreciendo líneas de investigación futuras.

\section{Discusión conceptual}

\section{E1 movimiento de pobladores en Chile}

El preguntarse por la posición de un campamento específico dentro del amplio movimiento de pobladores existente a fines de la década del 60 y principios de la del 70 supone la existencia de dicho movimiento. Sin embargo, como se verá, esta no ha sido siempre reconocida, por lo que cabe distinguir, en principio, qué se entenderá por movimiento de pobladores.

Pues bien, se entenderá al movimiento de pobladores, en primer lugar, como un movimiento social. Una clásica y operativa definición de estos la entrega Joachim Raschke, la cual se utilizará para verificar la pertinencia de considerar al movimiento de pobladores como tal. Para él, un movimiento social es: "Un actor colectivo movilizador que, con cierta continuidad y sobre las bases de una alta integración simbólica y una escasa especificación de su papel, persigue una meta consistente en llevar a cabo, evitar o anular cambios sociales fundamentales, utilizando para ello formas organizativas y de acción variables"10.

Respecto a la movilización, Raschke sostiene que esta no está asegurada por su institucionalización, por lo que la búsqueda activa de apoyos se convierte en la condición más relevante para su existencia. Sin duda esta fue una de las características fundamentales del movimiento de pobladores, el cual para hacer valer sus demandas debió permanentemente movilizar apoyos a su causa, como los de partidos políticos y sus representantes, o la iglesia católica.

Sobre una "cierta continuidad" del movimiento, de al menos varios años para Raschke, es lo que permitiría diferenciarlo de episodios colectivos cortoplacistas o acciones espontáneas de masas. El movimiento de pobladores efectivamente contó con varios años de continuidad, al menos hasta 1973, cuando se vería desarticulado por el golpe de Estado. Contando con antecedentes en movilizaciones llevadas a cabo por los habitantes de conventillos y otras formas de habitación popular a principios del siglo $\mathrm{XX}^{11}$, existe cierto consenso en definir el año 1957, específicamente a partir de la toma de terrenos que dio origen a la población La Victoria, como el punto de inicio de "una nueva estrategia de poblamiento", la cual "implicaba al menos dos pasos tácticos fundamentales, por una parte, potenciar las capacidades

${ }^{10}$ Joachim Raschke, "Sobre el concepto de movimiento social”, Zona Abierta, N 69, Madrid, 1994, 124.

11 Mario Garcés, 2005, op. cit., 59 y Mario Garcés, La revolución de los pobladores, treinta años después..., 2003, Disponible en internet:

http://www.ongeco.cl/wp-content/uploads/2015/04/La revolucion de los pobladores.pdf 
organizativas propias, y por la otra, mecanismos de presión sobre el Estado" ${ }^{12}$. Esta estrategia se convirtió en un ejemplo paradigmático de organización para los pobladores chilenos ${ }^{13}, y$ sería replicada con cada vez más fuerza de ahí en adelante.

En cuanto a la "alta integración simbólica" señalada por Raschke como una de las bases de un movimiento social, se refiere a la existencia de una "conciencia de pertenencia común" $" 14$ en su interior, desarrollada a partir de una diferenciación con un otro que está en contra de un nosotros. Esta conciencia de pertenencia entre los pobladores se habría desarrollado, sobre todo, a partir de su organización en torno a un objetivo común, después de décadas de precariedad habitacional: la lucha por un sitio propio en la ciudad. Adoptando una categoría desarrollada por las teorías funcionalistas de la DESAL ${ }^{15}$, los "pobladores" se identificaron como tales sobre todo en contraposición al Estado y a las empresas constructoras, a quienes demandaban las condiciones necesarias, al menos, para habitar decentemente en la ciudad.

Respecto a la escasa especificación del papel del movimiento, refiere a la baja diferenciación y fijación de roles que se da en su interior, pero que, sin embargo, existe, debido a una "superposición de elementos formales e informales" ". La existencia de organizaciones formales dentro del movimiento de pobladores, tales como comités de allegados, o arrendatarios, e incluso las organizaciones comunitarias fomentadas por la política de "Promoción Popular" llevada a cabo por el gobierno de Eduardo Frei Montalva (juntas de vecinos, centros de madres, etc.), serían ejemplos de ellas. En su interior coexistían, sin embargo, tanto dirigentes políticos como sindicales, activistas, simpatizantes, trabajadores de distinta índole, etc.

Por último, se encuentra el punto que se ha presentado como el más problemático a la hora de definir al movimiento de pobladores como movimiento social: sus metas y modos de alcanzarlas. Para Raschke "no es importante una meta que busque un cambio del sistema en su conjunto, pero sí el de, al menos, algunos elementos importantes del mismo"17, o fundamentales. Para los investigadores Enrique Pastrana y Mónica Threlfall, que estudiaron el movimiento de pobladores durante la Unidad Popular, éste consistía en "la expresión organizada de las reivindicaciones propias del frente poblacional", a saber, "todos los problemas sobre los cuales potencialmente los sectores populares pueden organizarse en su

\footnotetext{
12 Garcés, 2003, op. cit.

13 Alexis Cortés, "El movimiento de pobladores chilenos y la población La Victoria: ejemplaridad, movimientos sociales y el derecho a la ciudad”, EURE, N 119, vol. 40, Santiago, 2014, 240.

${ }^{14}$ Raschke, 1994, op. cit., 124.

${ }^{15}$ Centro para el Desarrollo Económico y Social de América Latina, fundado en 1961 y dirigido por el sacerdote jesuita Roger Vekemans, que con su teoría de la marginalidad influyó decisivamente en la reflexión acerca de los "pobres de la ciudad", a los que caracterizó como marginales, tanto por su posición geográfica en la ciudad (en las poblaciones "callampas", periféricas respecto al centro cívico e histórico de ella) como cultural en la sociedad (campesinos que al llegar a la ciudad moderna no lograban integrarse a ella), lo que llevó a definirlos como "pobladores", es decir "aquellos cuya existencia se reducía exclusivamente al acto de poblar, siendo 'nadie' en términos de significación social" (Boris Cofré, "Pensar la historia desde los movimientos sociales urbanos en Chile: los pobladores del Gran Santiago", Boletin de Geografía, N³0, 2009, 32).

${ }^{16}$ Raschke, 1994, op. cit., 124-125.

${ }^{17}$ Ibid, 125.
} 
lugar de residencia, para satisfacer necesidades de consumo colectivo o individual"18. Es decir el movimiento se definía, básicamente, por una "contradicción estructuralmente secundaria"19, ya que se situaba en el campo del consumo y no en el de la producción, constituyéndose como movimiento social en la década del 60, al articularse con la coyuntura de lucha de clases en ese entonces existente en Chile, mediante ciertas estrategias políticas que lo buscaron conducir, cada una de las cuales expresaba ciertas formas de acción tendientes a alcanzar sus metas (las cuales se especificarán más adelante).

Sobre todo el trágico desenlace que tuvo la "vía chilena al socialismo" provocó que esta definición marxista-economicista del movimiento de pobladores fuera puesta en entredicho, cuestionándose su misma existencia, ya que, por ejemplo, distintas orientaciones a la acción existentes entre los pobladores no se habrían resuelto nunca en un solo proyecto de cambio social $^{20}$. Para el sociólogo Eugenio Tironi, asimismo, el hecho de no haber generado una identidad colectiva particular significó que los pobladores no constituyeron un movimiento social propiamente tal, sino más bien uno de militantes ${ }^{21}$.

Sin embargo, para Raschke los movimientos sociales no "están fijados por principio a una forma de acción determinada, sea del tipo institucionalizado o del tipo de acción directa" 22 , siendo determinante en su nacimiento más que nada "la incapacidad del sistema institucional establecido para encontrar respuestas" 23 a sus problemáticas. Esta tesis se condice con las categorías desarrolladas por la "teoría de los procesos políticos de Charles Tilly y Sidney Tarrow" según la cual "la contestación política ocurre cuando oportunidades y restricciones políticas crean incentivos para que actores sociales, sin otros recursos más que la acción colectiva, actúen, mediante repertorios determinados, desafiando a autoridades o a grupos poderosos" $"$.

En cuanto al movimiento de pobladores, el historiador Mario Garcés, parafraseando a Sidney Tarrow, afirma "que el año 1957 se fue configurando una 'estructura de oportunidades políticas' favorable para los pobladores",25, tanto por agudas protestas sociales acaecidas dicho año como por la incapacidad del Estado de hacerles frente. Este, por lo tanto, "a partir de 1958 tuvo que reconocer progresivamente a los pobladores como interlocutores válidos" 26 , comenzando a desarrollar políticas habitacionales que respondieran a sus demandas. En la década del 60 este reconocimiento se haría cada vez más patente, llegando a su punto máximo durante los mil días en que gobernó la Unidad Popular.

Así, se sostiene que el movimiento de pobladores no solo existió como movimiento social entre 1970 y 1973, si no que cargaba con un desarrollo que puede retrotraerse hasta, al

\footnotetext{
18 Pastrana y Threlfall, 1974, op. cit.

${ }^{19}$ Castells, 1973, op. cit., 9.

20 Vicente Espinoza, "Historia social de la acción colectiva urbana: los pobladores de Santiago, 1957-1987”, EURE, N ${ }^{\circ} 72$, vol. 24, Santiago, 1998, pp. 71-84.

${ }^{21}$ Cortés, 2014, op. cit.

22 Raschke, 1994, op. cit., 126.

23 Ídem.

${ }^{24}$ Cortés, 2014, op. cit., 252-253.

25 Garcés, 2003, op. cit.

26 Ídem.
} 
menos, 1957. Una de sus formas organizativas más particulares fueron los campamentos, en los que se habrían generado formas embrionarias de poder popular.

\section{Los campamentos y el poder popular}

Experiencias de asentamientos urbanos surgidos sobre la base de tomas organizadas de terreno pueden rastrearse, al menos, desde 1945, intensificándose entre 1946 y $1947^{27}$. Estas tomas han quedado de cierta manera aisladas del relato que se ha formado sobre el movimiento poblacional, sin embargo, sobre todo por las condiciones socio-políticas represivas que les siguieron, con la proscripción del Partido Comunista incluida, el que tuvo presencia en ellas desde su origen ${ }^{28}$, vale decir.

No fue sino hasta 1957, con la toma de la ex Chacra La Feria, que devino en la población La Victoria ${ }^{29}$, que se desarrollaría plenamente el repertorio de acción y organización colectiva que caracterizaría al movimiento de pobladores de ahí en adelante, el que Mario Garcés resume de la siguiente manera:

Actuar por sorpresa (de preferencia en la noche) para evitar la represión y constituir el campamento por la vía de los hechos; establecer alianzas con los parlamentarios o las autoridades comunales, que en muchos casos posteriores actuarían como escudos frente a la represión; desarrollar una sólida organización previa en comités de sin casa y después comisiones de trabajo para defender y construir la población ${ }^{30}$.

La toma de terrenos a partir de entonces se haría cada vez más frecuente, configurándose Santiago como una ciudad en que "el símbolo inequívoco de la crisis social" pasó de ser la población callampa, como algo singular e inconexo, a "grandes áreas depauperadas" ${ }^{\prime 31}$, las que serían identificadas como campamentos ${ }^{32}$.

En ellos se desarrollarían formas organizativas sin duda originales, verdaderas experiencias de democracia directa, según Garcés ${ }^{33}$. Nacidos, por su ilegalidad, “en contradicción objetiva con el orden social", se vieron obligados "a utilizar formas propias de

\footnotetext{
${ }^{27}$ Jorge Rojas Flores, "La lucha por la vivienda en tiempos de González Videla: las experiencias de las poblaciones Los Nogales, Lo Zañartú y Luis Emilio Recabarren en Santiago de Chile, 1946-1947”, Izquierdas, N 39, Santiago, 2018, 9.

${ }^{28}$ Ibid, 29.

29 Población que ya en 1959 era denominada como "campamento", como lo demuestra el título de la tesis del arquitecto de la Universidad de Chile Sergio Tabilo, de ese año: "Rehabilitación de la población Campamento de La Victoria". De manera general esta denominación hace referencia más bien al carácter transitorio del asentamiento (en vías de urbanizarse y consolidarse con viviendas definitivas), que a su carácter político.

30 Mario Garcés, "Las tomas en la formación de Santiago", en: Nosotros los chilenos 5: el mundo de las poblaciones, Santiago, LOM, 2004, 14.

31 Gonzalo Cáceres, "Santiago de Chile. La capital de la izquierda", en Adrián Gorelik y Fernanda Arêas Peixoto (eds.), Ciudades sudamericanas como arenas culturales, Buenos Aires, Siglo Veintiuno.

32 Pastrana y Threlfall, en 1974, op. cit., los definieron como "asentamientos formados sobre la base de tomas organizadas de terreno urbano", a diferencia de las callampas y conventillos, formas antiguas de "ubicación residencial del proletariado" y las poblaciones, "conjuntos habitacionales planificados de vivienda".

33 Garcés, 2003, op. cit., 9.
} 
tratamiento de los diferentes problemas de la vida cotidiana" al mismo tiempo que, al fundarse en una reivindicación urbana, habrían tendido a acercarse "progresivamente a su 'normalización social', conforme la demanda social obtiene respuesta por parte de las instituciones públicas" ${ }^{34}$.

La relación de estos campamentos con las instituciones públicas, así como sus modos organizativos, sin embargo, habrían variado según el proyecto político que los conducía, al menos para quienes los investigaron en la década del 70. Así, para Pastrana y Threlfall se podían distinguir en ellos tres modelos político- organizativos: el asistencialista, asociado al proyecto llevado a cabo por la DC a partir de su gobierno, el participacionista, surgido "como respuesta de los partidos de izquierda tradicional" -PC y PS, principalmente- al anterior, identificándose con él, para hacer de la reivindicación habitacional "un medio de ampliación de las bases sociales de apoyo para su respectivo proyecto político, bajo una modalidad electoralista" y un modelo movilizador, asociado a campamentos liderados por el MIR, que convertía "las luchas poblacionales en un frente adicional del enfrentamiento de clases",35, compartiendo el objetivo general de construcción del socialismo con el modelo participacionista, pero postulando que esa construcción se daría solo a partir del enfrentamiento directo de clases ${ }^{36}$. Para dichos autores, en los campamentos identificados con este modelo se habrían generado "gérmenes de poder popular a nivel territorial" así como se haría, "posteriormente, en los comandos comunales" 37 . Los investigadores del CIDU coincidían, en general, con esta propuesta clasificatoria.

Años después Vicente Espinoza también caracterizaría el desarrollo del movimiento de pobladores en virtud de su relación con la institucionalidad política, identificando tres períodos hasta el golpe de Estado: el primero, de las tomas de terreno sucedidas desde 1957, puramente reivindicativo ("en nada político"38), el segundo, ligado a la estrategia de promoción popular fomentada por el gobierno democratacristiano y en el que la lógica reivindicativa se mantiene pero "se canaliza a través de la política de institucionalización o bien ella se asocia a la lógica crítica de los partidos de izquierda que buscan cambiar la naturaleza del sistema" "39, y el período de la Unidad Popular, en que las tomas "adquieren una significación política" ${ }^{40}$ en el sentido de

\footnotetext{
34 Equipo de Estudios Poblacionales CIDU, 1972, op. cit., 59.

35 Pastrana y Threlfall, 1974, op. cit.

${ }^{36}$ Dando cuenta de la distinción entre "gradualistas" y "rupturistas" a nivel del movimiento de pobladores antes y durante la Unidad Popular, la cual implicaba dos estrategias distintas para hacer la revolución en Chile: por etapas, institucionalmente, o destruyendo el aparato estatal vigente (Julio Pinto, "Hacer la revolución en Chile", en Julio Pinto (ed.), 2005, op. cit., 9-33.

37 Los cuales fueron "organismos creados por una comuna o varias comunas y que permitieron teóricamente la reunión, a nivel comunal, de delegaciones de obreros, campesinos, estudiantes, dueñas de casa y de las JAP o Comités de barrios" (Gaudichaud, Poder popular y cordones industriales. Testimonios sobre el movimiento popular urbano, 1970-1973, Santiago, LOM, 2004, 40). Principalmente dirigidos por el MIR, no habrían alcanzado "el nivel de organización y desarrollo de los Cordones Industriales" (Ibid, 42), las cuales fueron "organizaciones unitarias y transversales" que funcionaron sobre una base territorial y permitieron "la unión entre los diferentes sindicatos de un sector industrial preciso" (Gaudichaud, "Construyendo "poder popular": el movimiento sindical, la CUT y las luchas obreras en el periodo de la Unidad Popular”, en Julio Pinto (ed.), 2005, op. cit., 95).

${ }^{38}$ Espinoza, 1998, op. cit., 74.

${ }^{39}$ Ibid, 82.

${ }^{40}$ Ibid, 78
} 
que las reivindicaciones de los pobladores se buscaron integrar en el proyecto político estatal, mediante la así llamada participación popular, o bien se buscaron desligar de él a través de experiencias rupturistas, como Nueva La Habana (las que no habrían tenido éxito, de cierta manera abandonándolas el MIR a medida que avanzaban los mil días de la UP).

Otra caracterización del desarrollo del movimiento poblacional realizaría posteriormente Sebastián Leiva, dividiéndolo en dos momentos: el primero ligado a las estrategias reivindicativas urbanas, "caracterizada por la vinculación con el sistema político a través de la representación parlamentaria y la negociación política", relacionado a los partidos Comunista y Demócrata Cristiano, principalmente, y el segundo, relacionado a la irrupción del MIR en el movimiento, en que se conformó embrionaria y conscientemente poder popular, a partir de "la creación de nuevas formas de organización, que plantean una democracia participativa, y la articulación de las luchas del movimiento poblacional con las del resto del movimiento social, rompiéndose la lógica atomizante" ${ }^{41}$ hasta entonces predominante.

Si bien estas propuestas clasificatorias tienen diferencias en sus énfasis y valoraciones, coinciden en otorgarle una cualidad diferente a los campamentos conducidos por el MIR, o por lo menos negar que antes del advenimiento de la UP haya existido una intencionalidad política en los campamentos, tratándose simplemente de asentamientos originados para satisfacer una reivindicación habitacional, sobre la cual distintos partidos políticos intentaban realizar sus proyectos de transformación social.

Sin embargo, ellas pasan por alto modos organizativos y de acción autónomos que habían sido desarrollados por pobladores antes de la irrupción de la estrategia "rupturista" en el movimiento poblacional, como vimos, por ejemplo en La Victoria, toma en la que influyeron decisivamente militantes comunistas, quienes "fueron portadores de un proyecto que se afirmó en la experiencia de poder popular asociada a la administración autónoma del territorio y a la lógica de autoconstrucción" ${ }^{42}$ consecuencia de la misma. En esta toma, señala Alexis Cortés, se habrían anticipado "repertorios que serían leídos como novedad en los años setenta" 43 por los investigadores del CIDU, por ejemplo, o Pastrana y Threlfall, visión que sin duda influyó en las que posteriormente se desarrollarían, como las que se revisaron más arriba, invisibilizando al movimiento de pobladores como movimiento social, políticamente relevante, antes de fines de la década del 60, por lo menos.

Pareciera ser que el hecho de identificar formas de poder popular solo en campamentos liderados por organizaciones políticas radicales (el MIR, sobre todo, aunque también sectores del PS) en la coyuntura pre y post eleccionaria de 1970 obedece a una concepción clásica de este poder, marxista-leninista, que lo define como "la fuerza que es capaz de desplegar el pueblo en determinados procesos históricos con miras a la toma del poder" ${ }^{\prime 4}$, destruyendo el Estado burgués previamente. Otra manera de entenderlo es como un

\footnotetext{
${ }^{41}$ Leiva, 2002, op. cit., 110.

42 Alexis Cortés, Los comunistas y la toma de terrenos de La Victoria. A 50 años de una de las tomas más grande de Latinoamérica, 2007, disponible en internet:

http://www.generacion80.cl/documentos/docs/Los_Comunistas_Toma_La_Victoria.pdf

43 Cortés, 2014, op. cit., 247.

44 Sebastián Leiva, "Teoría y práctica del poder popular: los casos del Movimiento de Izquierda Revolucionaria (MIR, Chile, 1970-1973) y el Partido Revolucionario de los Trabajadores - Ejército Revolucionario del Pueblo
} 
"proceso de democratización del Poder desde las bases" formas, embrionarias al menos, de poder popular se hayan dado tan tempranamente como en 1957, e incluso antes, en tomas y campamentos organizados por militantes PC, ligado a la estrategia "gradualista" de construcción del socialismo.

Dicha concepción es la que Salvador Allende habría tenido del poder popular, "consistente en respaldar las medidas del 'gobierno popular' y los espacios obtenidos dentro del aparato estatal", no como "una instancia paralela al Estado, que lo confrontara y destruyera desde fuera de la institucionalidad" ". Así, Allende habría considerado que las formas de democracia directa generadas en los campamentos (así como en fábricas, en torno a los cordones industriales), siendo encauzadas institucionalmente, hacían posible la construcción de un poder popular complementario al poder del gobierno, "como elemento clave en el proceso de democratización/socialización del poder político" ${ }^{47}$ que anhelaba. Sin embargo, esta visión no habría sido compartida por gradualistas - que se aferraban a las maneras clásicas de administrar el poder, estatalmente- ni rupturistas -que pretendían crear una dualidad de poderes, que acabara con el poder burgués- siendo, además, anulada por el golpe de Estado de 1973.

Así bien, ¿puede afirmarse que la conformación de poder popular a partir de los campamentos, en la coyuntura pre y post UP, estuvo exclusivamente ligada a los que estuvieron asociados al MIR, o también se dio en otros en la misma época, más cercanos a tendencias gradualistas? Una forma de responder esta interrogante es analizando las características que se dieron en un enorme campamento, contiguo al Nueva La Habana, pero mucho menos estudiado: el campamento Unidad Popular.

\section{Presentación y análisis de resultados: campamento Unidad Popular (1970-1973)}

\section{La toma del terreno}

Entre 1969 y 1970 las tomas de terreno se multiplicaron en todo el país, a partir de una coyuntura favorable para ellas, tanto por las críticas al gobierno democratacristiano luego de la violenta represión con que respondió a una toma de terrenos en Pampa Irigoin, Puerto Montt, que culminó con siete pobladores muertos (9 de marzo de 1969), como porque "estaban en juego los apoyos ciudadanos para la próxima elección"48 , de septiembre de 1970. Joaquín Duque y Ernesto Pastrana, en 1972, contabilizaron 8 "ocupaciones de terrenos de pobladores"

(PRT-ERP, Argentina, 1973-1976)", Tesis para optar al grado de Magíster en Historia, mención Historia de América, Universidad de Santiago de Chile, 2007, 21.

45 Hugo Cancino, La problemática del poder popular en el proceso de la vía chilena al socialismo 1970-1973, Aarhus, Aarhus University Press, 1988, 16.

46 Rolando Álvarez Vallejos, "La Unidad Popular y las elecciones presidenciales de 1970 en Chile: la batalla electoral como vía revolucionaria”, Osal, N²8, Año XI, Buenos Aires, 2010, 233.

${ }^{47}$ Cancino, 1988, op. cit., 225.

${ }^{48}$ Garcés, 2004, op. cit., 25. 
en 1968, 73 en 1969 y 220 en 1970 49 , lo que demuestra el explosivo aumento de tomas de terrenos que hubo tal año. De ellas, la primera se realizó el domingo 11 de enero, en La Florida, comuna periférica de Santiago.

En el diario El Siglo del día siguiente se señalaba que 1.200 familias agrupadas en comités de arrendatarios y allegados, unidos en un solo "Comando de las Familias Inestables y Sin Casa de Ñunoa"50 (presidido por Alejandro Galán) se habían tomado terrenos ubicados en la intersección de las calles Macul con Departamental. Esto por la tramitación a la que habían sido objeto por más de un año por las autoridades para solucionar su "problema habitacional", según Galán, "a pesar de contar con 520 millones de pesos en cuotas de ahorro previo Corhabit" 51 (Corporación de Servicios Habitacionales).

La toma habría sido una decisión de las bases: "Al interior de la organización, específicamente en las bases, se determina que la única solución era la 'toma'. Por lo tanto, se da paso a planificarla" ${ }^{52}$. La planificación, sí, estuvo a cargo de la dirección del comando, exclusivamente, como relataba una pobladora del comité "Unión hace la Fuerza" a Andrés Moreno en 1989: "por ahí supe que los dirigentes no informaban mucho, por el temor a que alguna información saliera de esta organización", la que contaba con "un cordón de apoyo previo" que la facilitó, formado por "parlamentarios y regidores del PC, también la FECH y algunos profesionales y organizaciones sociales" ${ }^{23}$, como juntas de vecinos de los barrios en los que se formaron los comités (Santa Julia, en la actual comuna de Macul, por ejemplo).

Cerca del mediodía llegó el Grupo Móvil de Carabineros: "un fuerte destacamento de efectivos policiales portando fusiles, lanzabombas de gas, lumas, cascos y los llamativos escudos tipo gladiador- De inmediato cercaron el extenso terreno" ${ }^{54}$. El desalojo, sin embargo, se impidió gracias a la intervención de los diputados del PC Luis Figueroa (también presidente de la CUT) y Orlando Millas. A ellos también se sumaron Alejandro Rojas y Juan Manuel Alcoholado, presidente y vocal de la FECH, respectivamente, que comprometieron la ayuda de esta federación a los pobladores, cuya lucha, indicaron, "es la lucha de la FECH" 55 .

En el oficialista diario La Nación, en tanto, se contabilizaron solo 570 personas en la toma $^{56}$, identificándose el terreno como propiedad de la sucesión Chacón Zamora, de 250

\footnotetext{
49 Joaquín Duque y Ernesto Pastrana, "La movilización reivindicativa urbana de los sectores populares en Chile: 1964-1972”, en Alfredo Rodríguez y Paula Rodríguez (eds.), Santiago, una ciudad neoliberal, Quito, Organización Latinoamericana y del Caribe de Centros Histórico (OLACCHI), 2009, 63.

${ }^{50} \mathrm{El}$ que "comenzó sus gestiones en Enero de 1969" (Andrés Moreno, "Campamento Unidad Popular (Villa Los Copihues)", en Hanny Suckel (ed.), Historias Locales I, Santiago, Jundep, 1990, 40) y que estaba afiliado, según declaración oficial de CORHABIT publicada en el diario El Mercurio (13 de enero de 1970, 23), a una "Federación Provincial", dirigida por Juan Araya, "histórico dirigente de los pobladores, vinculado al Partido Comunista y que había participado en varias tomas de Barrancas” (Garcés, 2005, op. cit., 66) y Quinta Normal.

${ }^{51}$ El Siglo, 12 de enero de 1970, 5.

52 Moreno, 1990, op. cit., 41.

${ }^{53} \mathrm{Idem}$.

${ }^{54}$ El Siglo, 12 de enero, 5.

55 Idem.

${ }^{56}$ Esta notables diferencia numérica respecto a lo informado por El Siglo no era algo nuevo: como señalara Mario Garcés, en relación a la toma de Herminda de la Victoria, de 1967, "como había ocurrido antes y ocurriría después, una verdadera disputa política y comunicacional se verificó con relación al número de pobladores involucrado en esa toma" (2004, op. cit., 20).
} 
metros de largo por 50 de ancho, iniciándose su ocupación a las cinco de la madrugada. Según este periódico, los pobladores eran encabezados por el dirigente Luis Aedo, quien señaló que "la medida ilegal obedecía a la tramitación de que habían sido objeto por parte de la CORVI" 57 (Corporación de la Vivienda), aun cuando esta corporación les había prometido casas o sitios para marzo. Esto ya que no pretendían ser más tramitados, ni realizar una mudanza en invierno.

A las 11 habrían llegado los efectivos de Carabineros, "quienes procedieron a parlamentar con los pobladores. Se trataba de convencerlos de la necesidad de que abandonaran los terrenos sin que se produjeran incidentes. Sin embargo los pobladores se negaron terminantemente a acatar la orden policial" ${ }^{58}$. Momentos después llegaron a mediar políticos de izquierda ${ }^{59}$, como también señalaba El Siglo. Esta mediación permitió que no fueran desalojados, a la espera de que el día lunes "a través de la gestión del Intendente de Santiago, se llegue a una solución que deje a todos conformes".

Rápidamente los pobladores comenzarían a organizarse en el terreno: se formaron "brigadas recolectoras de ramas" y "refugios improvisados para protegerse del calor" ocupantes "instalaron rápidamente sus mejoras" y formaron un comité de vigilancia, encargado de "empadronar a los pobladores",

En El Mercurio se agregaba que a las 18 horas se retiró una gran cantidad de Carabineros, quedando solo "un reducido grupo resguardando el lugar, para impedir el acceso de personas de otros comandos" ". También se especificaba que, además del presidente Alejandro Galán, el Comando estaba dirigido por Sergio Aliaga, vicepresidente, y Paul Maldonado, secretario general, y que ese día visitó la toma el alcalde de La Florida y el Subdelegado de Gobierno. Respecto a la propiedad del terreno, se cita a Aliaga, quien dijo que pensaban que era de la CORVI, no de un particular" "pero de todas maneras no nos iremos hasta que no se nos dé solución", y que carecía de todo tipo de urbanización, como red de agua potable o alcantarillado.

Luego de que "las autoridades comunales de La Florida y ejecutivos del Ministerio de la Vivienda permitieron que las familias se quedaran en los terrenos mientras se busca una rápida solución a su problema" ${ }^{\prime \prime}$, los pobladores denominaron al así ya instaurado campamento como "Unidad Popular", debido "a la gran afinidad que existía en aquel entonces por el gobierno que se aproximaba" ${ }^{\prime 65}$, al cual numerosas familias se habían incorporado tras la toma.

${ }^{57}$ La Nación, 12 de enero de 1970, 14.

58 Idem.

59 Según La Tercera de La Hora (12 de enero de 1970, 5) antes de que llegara el Grupo Móvil ya estaban en la toma Luis Figueroa, Aníbal Stuardo (regidor comunista de La Florida), el subdelegado de Gobierno de La Florida, llegando después Orlando Millas y María Marchant (regidora comunista de Ñuñoa).

${ }^{60}$ Las Noticias de Última Hora, 12 de enero de 1970, 7.

${ }^{61}$ Las Noticias de Última Hora, 11 de enero de 1970, última página (s/n).

62 El Mercurio, 12 de enero de 1970, 30.

${ }^{63}$ Según Alejandro Galán, sin embargo, Corhabit había estado negociando previamente con "las dueñas del predio para comprarlo e instalarnos en este lugar. Son terrenos que hace años nadie trabaja y están abandonados" (Las Noticias de Última Hora, 12 de enero de 1970, 7).

${ }^{64}$ El Siglo, 13 de enero de 1970, 1.

65 Moreno, 1990, op. cit., 44. 
En resumen, puede señalarse que la información disponible sobre la toma de terrenos que dio origen al campamento Unidad Popular permite verificar cómo esta se asimiló, con exactitud, al repertorio de acción y organización colectiva característico del movimiento de pobladores: una acción sorpresiva, realizada a altas horas de la madrugada, el establecimiento de alianzas con parlamentarios (en este caso exclusivamente del PC) y autoridades comunales que permitieran evitar la represión, todo sobre la base de un trabajo previo en comités de sin casa que devendría en la formación de comisiones de trabajo al interior del campamento, las que permitirían "defender y construir la población"

Así, se confirman las afirmaciones realizadas por Boris Cofré respecto al campamento Unidad Popular como modelo en el cual el PC se "transformaba en representante de los pobladores y mediador entre éstos y el Estado. Esta acción conjunta permitió consolidar la toma de sitio y transformarla en un campamento que iniciaría nuevas luchas (por equipamiento urbano) y adheriría electoralmente al PC ${ }^{967}$. El desarrollo de dicha adhesión electoral, así como de nuevas formas organizativas y de lucha en este campamento, se analizarán a continuación.

\section{La organización del campamento}

Prontamente se organizaron en el campamento comités encargados de salud y una guardería infantil, así como se construyeron "pozos sépticos fuera de los terrenos", utilizados como baños, contando con uno cada manzana ${ }^{68}$ (unidad en que se distribuyeron los habitantes del campamento, según sus comités de origen). Respecto a esta división, un poblador relataba en 1989 que, al principio, "a cada familia le correspondía 3 metros cuadrados y ahí había que tratar de acomodarse y empezó la construcción de piezas, techo. Después de un tiempo, los estudiantes de Arquitectura hicieron la distribución de sitios"69, en colaboración con el delegado o presidente de cada comité. Misma dinámica que se había producido, cabe destacar, en el campamento de La Victoria.

Cuatro días después de la toma el campamento ya contaba con dos mil familias, "viviendo en medio de pastizales azotados por el sol"70. Más personas, aún, se habrían intentado sumar, pero al no ser parte del comando original no se les había permitido. Un dirigente del campamento señalaba, posteriormente, respecto a un grupo de familias ajenas al comando que habían logrado instalarse en el terreno, que las autoridades les exigían que salieran, por lo que tendrían "que acatar esa medida, pues no podemos romper nuestro largo movimiento",

Un poblador que participó de un grupo de vigilancia, recordaba en 1989 que "ahí cada uno ponía un poquito de café, azúcar, pan. Se marchaba en equipo bien organizado"72. Otra pobladora señalaba que este grupo, denominado comité, se organizó el mismo día de la toma, y

\footnotetext{
${ }^{66}$ Garcés, 2004, op. cit., 14.

${ }^{67}$ Cofré, 2011, op. cit., 144.

${ }^{68}$ La Tercera de La Hora, 14 de enero de 1970, 9.

${ }^{69}$ Moreno, 1990, op. cit., 46.

${ }^{70}$ El Siglo, 15 de enero de 1970, 12.

${ }^{71}$ El Siglo, 22 de enero de 1970, 9.

72 Moreno, 1990, op. cit., 48.
} 
que no era de "autodefensa", sino que de vigilancia ${ }^{73}$. Su función, en esta etapa de formación, por lo menos, era, por tanto, más que nada de protección de la toma, sin llegar a ser necesaria su conformación a la manera de las "milicias populares" que se desarrollaron en campamentos asociados al MIR sobre todo por la amenaza represiva que los acechaba en esa época (gobierno DC), ya que no contaban con las alianzas político-institucionales que les permitieran mediar con la fuerza pública.

En cuanto a la organización y tratamiento de los problemas de salud al interior del campamento, puede señalarse que tan solo 11 días después de la toma este ya contaba con una policlínica, a cargo de "jóvenes comunistas" y una "enfermera que los asesora, Elena Weiss", la que atendía las necesidades más básicas de la población, conformada entonces por 2.016 familias viviendo en un "hacinamiento impresionante". También contaban, según indicaba el secretario de actas del comando, Alejandro Álvarez, a El Siglo, con "la asistencia de la Facultad de Medicina y algunos médicos particulares que han ofrecido sus servicios, como es el caso de una hija de la parlamentaria María Marchant. También los estudiantes de arquitectura han hecho su aporte planificando el ordenamiento de las carpas para así controlar mejor la higiene y la vigilancia" ${ }^{74}$. Asimismo, Álvarez afirmaba que los carabineros solo iban en la noche a ayudarlos en la vigilancia, la que constaba de una guardia permanente de 60 pobladores, vigilando en el día las mujeres y en la noche los hombres.

Mientras tanto, los habitantes del campamento, aún sin solución habitacional definitiva, realizaban las gestiones pertinentes para que la que el gobierno les diera fuera en la misma comuna. Sin embargo, este se negaba a construir viviendas en esos terrenos, desde un principio, por considerarlos "pantanosos e imposibles de ser urbanizados"

Durante su campaña presidencial, Salvador Allende visitó el campamento, comprometiéndose con los pobladores a darles solución a su demanda habitacional, a quienes les dijo "ustedes han dado a este campamento la organización de una ciudad... hay un ejemplo de disciplina, de trabajo colectivo, de respeto a las jerarquías y muestra lo que podrá hacer el pueblo, el gobierno popular" ${ }^{\text {"76 }}$. Durante este "movimiento de elecciones, el partido Comunista era fuerte" ${ }^{\text {,77 }}$ recordaba al respecto una pobladora en 1989.

Puede confirmarse, así, la adhesión electoral que los pobladores del campamento tenían con el PC, o, por lo menos, con la coalición de partidos de la Unidad Popular. Se desconoce, sí, si este campamento se originó, como señalara Manuel Castells en 1973 respecto a los campamentos asociados a la Unidad Popular, como una articulación entre una reivindicación urbana y "una estrategia política, en este caso, la formación de CUP (Comités de Unidad Popular, órganos de movilización de base creados durante la campaña electoral de 1970) y el apoyo electoral" ${ }^{78}$.

Más que dichos comités electorales, sin embargo, puede sostenerse, a partir del análisis de las fuentes consultadas, que fueron los comités, y comandos, de los "sin casa", ligados al PC desde mediados del siglo XX, los que estuvieron a la base de la conformación de este

${ }^{73} \mathrm{Ibid}, 45$.

${ }^{74}$ El Siglo, 22 de enero de 1970, 9.

${ }^{75}$ El Mercurio, 13 de enero de 1970, 23.

${ }^{76}$ El Siglo, en Moreno, 1990, op. cit., 50.

${ }_{77}$ Moreno, 1990, op. cit., 50.

${ }^{78}$ Castells, 1973, op. cit., 25. 
campamento, sobre todo considerando que el comando de los sin casa de Nuñoa, como se señaló, comenzó a funcionar en enero de 1969, un año antes de que se proclamara al candidato presidencial de la Unidad Popular, y que realizaran la toma de terrenos del 11 de enero de 1970.

La organización que se dio al interior del campamento a partir de la toma se asemejó a las formas organizativas que típicamente el movimiento de pobladores había desarrollado hasta entonces, con la conformación de comités, "comisiones" o "frentes",79 de vigilancia y salud, por ejemplo, así como alianzas con escuelas de arquitectura y salud para organizar la vida al interior de él.

La apreciación de esta organización por parte del entonces candidato a la presidencia Salvador Allende, como un "ejemplo de disciplina" que mostraba lo que podría "hacer el pueblo, el gobierno popular" demuestra su visión de estas prácticas como enriquecedoras de la democracia que pretendía institucionalizar con miras al socialismo, más directa, participativa y "popular" que la hasta entonces conocida, la cual sería "más auténtica cuando más inmediato y directo" fuera su ejercicio ${ }^{80}$.

\section{Consolidación del campamento tras el triunfo de la Unidad Popular}

Eventualmente, como se sabe, Allende sería elegido presidente, y durante su gobierno se le dio una solución a los pobladores del campamento: se construiría en esos mismos terrenos, y otros colindantes hacia el sur, cruzando el Zanjón de la Aguada, una población para ellos, la que tendría el mismo nombre, "Unidad Popular". Ella constaría de viviendas y blocks de departamentos. Una pobladora recordaba en 1989 que "la gente estaba contenta, se pensaba que todo se iba a dar bien y así fue (...) El gobierno de Allende dio una solución, él estuvo en el campamento, hizo promesas y las cumplió" 81 .

Durante 1971 se formaría la primera junta de vecinos del campamento, cuyo surgimiento un poblador vinculaba, también en 1989, directamente con la visita de Allende: "cuando se fue la cosa fue cambiando, había un Presidente de la Junta de Vecinos, delegados, etc." 82 . Con el correr del tiempo, además, se instalaron "un club deportivo, una escuela, una capilla, una canasta popular y un policlínico con dos ambulancias donadas por el Presidente. A los años comenzaron a construir los edificios y casas" 83 .

Según los testimonios recogidas por Andrés Moreno, en esos años "se apreció un cambio en la gente, tenían metas más profundas, trabajaron con ahínco dando pasos concretos". Se daban distintas formas de solidaridad, como por ejemplo el hecho de que el club deportivo, mediante "cuotas sociales", aportaba dinero "para los radieres" con que se construía el policlínico ${ }^{84}$.

\footnotetext{
${ }^{79}$ Garcés, 2005, op. cit., 61.

80 Allende, 1973, en Cancino, 1988, op. cit., 335).

${ }^{81}$ Moreno, 1990, op. cit., 50.

${ }^{82}$ Idem.

${ }^{83}$ Ibid, 51.

${ }^{84}$ Ibid, 48.
} 
Dicho policlínico devino en un consultorio, en $1972^{85}$. En él trabajó la Dra. Laura Elena Gálvez, quien también ejercía labores en el consultorio Dr. Ernesto Che Guevara del campamento Nueva La Habana, así como en el Hospital Sótero del Río ${ }^{86}$.

En cuanto a la instalación de una escuela en el campamento, esta fue realizada el año 1971. "Era de las llamadas Escuelas Buses. Como plan piloto, en los campamentos se instalaron microbuses dados de baja" ${ }^{\text {" }}$. En ella todos los profesores eran estudiantes universitarios, salvo el Rector, que era Profesor Normalista y "otro colega que era bastante mayor que todos nosotros" 88 , recuerda María Eugenia Lorenzini, entonces estudiante de Pedagogía en el Instituto Pedagógico de la Universidad de Chile, simpatizante del MAPU, quien trabajó como profesora básica en esta escuela.

En general, las fuentes consultadas permiten deducir que, a partir del triunfo electoral de la Unidad Popular, la vida en el campamento había cambiado para mejor: "como en el 71 la gente ya estaba organizada, tenían sus mejoras, no estábamos en carpas" 89 señalaba un poblador en 1989. Asimismo, "se pagó por el agua (la red), para la luz la gente se colgó primero en los cables que pasaban al frente, luego se pusieron de acuerdo, todos pusieron plata, salieron los cables y se tiraron por la manzana" 90 . Para otro poblador toda la experiencia de organización desarrollada en el campamento fue "enriquecedora, estaba recién casado, tenía trabajo, no me faltó nada, tuve acceso a estudiar en el INACAP patrocinado por el trabajo" .

La construcción de la población, en tanto, sería ejecutada directamente por los pobladores: "de acuerdo con información proporcionada a la prensa por el dirigente Aliro Gutiérrez los planes de ejecución directa se pondrían en marcha también en la Población Nueva Habana, Unidad Popular y La Pincoya" "92. Esta se iniciaría después de 1971, año en que se creó un departamento de "Ejecución Directa" en el MINVU, dándosele trabajo en ella "a los cesantes conformada por la mayoría del campamento" 93 .

Todos los logros en cuanto a la reivindicación habitacional por la que se formó el campamento (vivienda propia) y a equipamiento urbano (consultorio, escuela, etc.) anteriormente referidos, se consiguieron una vez que la Unidad Popular asumió el gobierno. Esto parece confirmar las afirmaciones respecto a que este campamento, en particular, y todos los que estuvieron ligados al PC en esta época, se habrían relacionado asistencialmente con el gobierno, lo que no les permitió superar una "lógica atomizadora de la lucha poblacional"," que generara "procesos autogestionarios para resolver los problemas básicos de los pobladores" $" 95$ ni una coordinación con otros sectores, como el obrero. A continuación, se

85 Ibid, 52.

86 Pascale Bonnefoy Miralles, Terrorismo de Estadio. Prisioneros de guerra en un campo de deportes, Santiago: CESOC, $2005,57$.

87 Revista Docencia, La educación hace treinta años: vivencias de diversos actores, 2003, disponible en Internet: http://www.revistadocencia.cl/new/wp-content/pdf/20100730003400.pdf

${ }^{88}$ Idem.

89 Moreno, 1990, op. cit., 53.

${ }^{90}$ Ibid., 52.

${ }^{91}$ Ibid., 54.

92 Garcés, 2005, op. cit., 70.

93 Moreno, 1990, op. cit., 50.

${ }^{94}$ Leiva, 2002, op. cit., 123.

${ }^{95}$ Ibid, 122. 
intentará ahondar en esta situación, relativa a la relación de la política y el campamento, y sus pobladores.

\section{Movilización y dirección política del campamento}

Una interesante afirmación sobre el campamento Unidad Popular y su relación con los partidos políticos de la época se encuentra, como se ha indicado anteriormente, en el artículo "Movimiento de pobladores y lucha de clases en Chile" de Manuel Castells, publicado en 1973. En él, el autor indica que "el 11 de enero los partidos obreros, PC y PS realizaron una gigantesca ocupación de terrenos en La Florida (hoy campamento "Unidad Popular"), Santiago, con anterioridad incluso al comienzo de las tomas del MIR en la capital""

Años después Castells reafirmaría esta aseveración en su libro "La ciudad y las masas", indicando que "el pluralismo político al interior de los campamentos era raro, excepto entre Socialistas y Comunistas (por ejemplo, el campamento más grande, Unidad Popular, era liderado conjuntamente por ambos partidos)"97.

Esta identificación de la toma, y el campamento, como resultado de una planificación conjunta entre el PC y el PS no se encuentra en ninguna otra de las fuentes que hacen referencia a la toma de terrenos, como se pudo apreciar. Un artículo publicado el año 1972 por investigadores del CIDU ${ }^{98}$ (entre ellos Castells) puede dar luces respecto a esta situación.

Éstos habían realizado, entre agosto y septiembre de 1971, una encuesta directa en 25 campamentos del Gran Santiago, y dos de regiones, "con el fin de construir una información que hasta ahora no existe y cuyas fuentes desaparecerán a corto plazo conforme los campamentos sean absorbidos" y de "cubrir toda la gama política y una amplia variedad de situaciones ecológicas (tamaño y ubicación, etc.)" ", las que fueron aplicadas a un grupo de informantes representativos de cada campamento. Según los autores "todos los campamentos importantes de Santiago (numérica y políticamente) fueron incluidos en la muestra" "100. Entre ellos se incluyó al "Unidad Popular", que representaba a 2.500 familias, siendo el segundo más numeroso, después del "Junta Adelanto", de la comuna de Barrancas, representativo de 2.900 familias (pero del cual, curiosamente, no se encuentran mayores referencias en la bibliografía existente sobre el movimiento de pobladores).

Los resultados de esta encuesta se analizaron y presentaron en el artículo "Reivindicación urbana y lucha política", de 1972. En él se categorizó a los campamentos estudiados según la línea política predominante en cada uno, según "ciertas condiciones (tendencias fundamentales)", señalando, sí, que no podía "hacerse una correspondencia término a término entre líneas y organizaciones", dada "la complejidad del actual movimiento popular chileno", en el que "las distintas tendencias (y no fracciones) de un mismo partido

\footnotetext{
${ }^{96}$ Castells, 1973, op. cit., 25.

${ }_{97}$ Manuel Castells, The city and the grassroots: a cross-cultural theory or urban social movements, Berkeley, University of California Press, 1983, 201 (traducción propia).

98 Específicamente Manuel Castells, María Teresa Chadwick, Rosemond Cheetham, Antonieta Hirane, Santiago Quevedo, Teresa Rodríguez, Gastón Rojas, Jaime Rojas y Franz Vanderschueren (Equipo de Estudios Poblacionales CIDU, 1972, op. cit., 56).

${ }^{99}$ Equipo de Estudios Poblacionales CIDU, 1972, op. cit., 59.

100 Ibid, 80 .
} 
pueden reflejar, en la práctica de los campamentos, líneas que no son las que se atribuyen, en general, al partido general"101.

Los campamentos estudiados se dividieron en cinco tipos, según la línea política predominante en cada uno: el A, que procuraba "radicalizar políticamente el proceso"102, el B, que buscaba "la satisfacción de sus reivindicaciones de vivienda y el triunfo electoral. Una vez obtenido éste, se trata de crear los canales para maximizar la rápida solución de los problemas concretos del campamento a partir de una intervención del Estado"103, el C, caracterizado por una alternancia entre las líneas A y B, "pero con la peculiaridad de que el soporte organizativo (...) reposa en un arraigado caudillismo" 104 , el D, caracterizado como asistencialista antes de la asunción del gobierno por parte de la Unidad Popular, pasando a una orientación reivindicativa después de esto, $\mathrm{y}$, finalmente, el $\mathrm{E}$, originado como el $\mathrm{D}$, pero que devino en asistencialismo hacia el gobierno de la UP una vez que este lo asume.

Lamentablemente para el interés de esta investigación, como una manera de mantener la confidencialidad de sus informantes y campamentos, en el artículo no se explicitó qué campamento se asociaba a cada línea política. Sin embargo, a partir de las caracterizaciones de cada línea y sus campamentos asociados, puede deducirse que el campamento Unidad Popular fue más cercano al tipo de línea B que a las demás. La organización política representativa de esta línea (no señalada, pero muy probablemente el PC) dirigía tres de los campamentos estudiados, así como "dos sectores de campamentos desgajados de otros"105. De estos cinco campamentos, tres tenían una dirección surgida de los comités sin casa, como el Unidad Popular, y dos una "directamente nombrada por la organización" (el PC). De los tres primeros, solo uno realizaba plenamente la línea $\mathrm{B}$, teniendo como base social predominante la "Aristocracia obrera" ". Considerando poco probable que se trate del Unidad Popular, ya que éste estaba formado tanto por obreros del sector tradicional como del informal (de la construcción, sobre todo), se presume que correspondería a uno de los otros dos: en ambos casos la base social predominante eran la "aristocracia obrera" y obreros, su estrategia dominante de relación con la organización política era la asistencia material (y no la clientela electoral, como en otros casos) y presentaban un "mediano nivel de servicios" y una "puesta en cuestión de la organización". El primero de ellos (identificado en el artículo como "Campamento 3") en tanto, representaba parcialmente la línea B, no presentando conflictos internos con la línea A (radical), y un mediano nivel de movilización institucional, mientras el segundo ("Campamento 4") sí presentaba conflictos internos con la línea A, y una puesta en cuestión de la línea dominante en general, más allá de la organización, así como un mediano nivel de apoliticidad.

\footnotetext{
101 Ibid, 69.

102 Idem.

103 Ibid, 70.

104 Idem.

105 Idem.

106 Ibid, 72.

107 Entendida, por estos investigadores, como "una fracción obrera con nivel de ingresos e instrucción muy superiores al de los obreros viviendo en campamentos" (Equipo de Estudios Poblacionales CIDU, 1972, op. cit., 72).
} 
La afirmación de Castells respecto a una dirección conjunta del PC y el PS en el campamento Unidad Popular puede dar cuenta de dichos conflictos, tanto con la línea A (asociada al MIR y sectores del PS), como con la organización, y línea, dominante (asociada al PC). Sin embargo, en el artículo de los investigadores del CIDU no existen antecedentes que permitan determinar con certeza a cuál campamento de los que caracterizaron específicamente correspondía el Unidad Popular.

Empero, ciertos antecedentes pueden proporcionar datos que ayuden a profundizar en la posible existencia de un conflicto interno a nivel de línea política en el campamento Unidad Popular. Por ejemplo, un poblador relataba, en 1989, cómo se movilizaron para lograr la extensión de un recorrido de micro, de manera que terminara en el campamento y no tuviesen que caminar en la oscuridad un largo trecho para movilizarse hacia y desde el centro de Santiago:

Con unos compañeros fuimos a buscar las micros (Agrícola con Macul) las trajimos y las encerramos en un Parvulario que había y no se les dio salida; al otro día llegó el compañero Daniel Vergara con el finado Carlos Cortés ${ }^{108}$, para que le diéramos salida a las micros, estábamos con palos apoyándonos, no había atrevimiento, era para que las micros llegaran hasta acá, no para hacer un 'mal daño"' 109 .

Este relato parece indicar que no siempre se esperaba que la asistencia y los adelantos llegaran directamente desde el gobierno hacia el campamento, o bien que fueran solicitados institucionalmente por la dirigencia a las autoridades, si no que podían ser reivindicados autónomamente, mediante acciones directas, como esta toma de micros, la cual tuvo que ser resuelta con la intervención de importantes autoridades del gobierno. Este hecho puede dar cuenta de un conflicto a nivel de modos de organización y acción presentes en el interior del campamento, aunque no es suficiente para sostenerlo por sí solo.

Después de la toma de micros también lograrían la pavimentación, "con el esfuerzo de dirigentes del campamento" "110, lo que pareciera acercarse más a una movilización del tipo institucional, en comparación a la anterior.

Un interesante antecedente respecto a la problemática de la línea política dominante en el campamento, fue encontrado en internet a principios del año 2016 (específicamente en la red social Facebook), pero no se pudieron recabar mayores datos sobre él, ni hallar, desde entonces, a quien allí lo compartió. Se trata de una fotografía en blanco y negro que muestra una concentración de pobladores, la mayoría de los cuales aparece portando banderas del MIR (así como dos, al menos, luciendo cascos con la sigla FTR pintada, probablemente abreviatura de Frente de Trabajadores Revolucionarios ${ }^{111}$ ). Sin embargo, al medio se puede apreciar a un grupo de pobladores portando un lienzo que dice "Campamento Unidad Popular. Partido Socialista", con el logo de dicho partido al centro:

108 Subsecretario del Interior y Ministro de Vivienda y Urbanismo, respectivamente, del gobierno de la Unidad Popular en ese entonces (1971).

109 Moreno, 1990, op. cit., 51.

${ }^{110}$ Idem.

111 Entonces novedosa "tendencia sindical bajo influencia esencialmente del MIR" (Gaudichaud, 2005, op. cit., 89). 
Aunque quien compartió esta imagen sostenía que fue tomada en el campamento Unidad Popular, resulta más plausible sostener que se sitúa en el contiguo campamento Nueva La Habana, dada la gran cantidad de banderas del MIR, ya que en ninguna fuente se menciona al MIR como una organización política que haya dirigido, o haya tenido una influencia importante, en el primero. Sin embargo, daría cuenta del pluralismo político que existió al interior del campamento Unidad Popular, pudiendo converger en él liderazgos asociados al PC como al PS, como sostuvo Castells (en 1973 y 1983), los que posiblemente (como muestra la imagen respecto al PS, al menos) tuvieron acercamientos con el MIR, que dirigía un campamento a escasos metros de él.

Una dirección conjunta PC-PS, sí, no se habría dado en los orígenes del campamento. Esto se puede deducir a partir de las diversas fuentes que tratan el tema de la toma de terrenos de la que surgió, todas las cuales hablan de una influencia (si no dirección) del PC en ella. De hecho, en la revista Punto Final de marzo de 1970 ( 2 meses después de realizada la toma), se

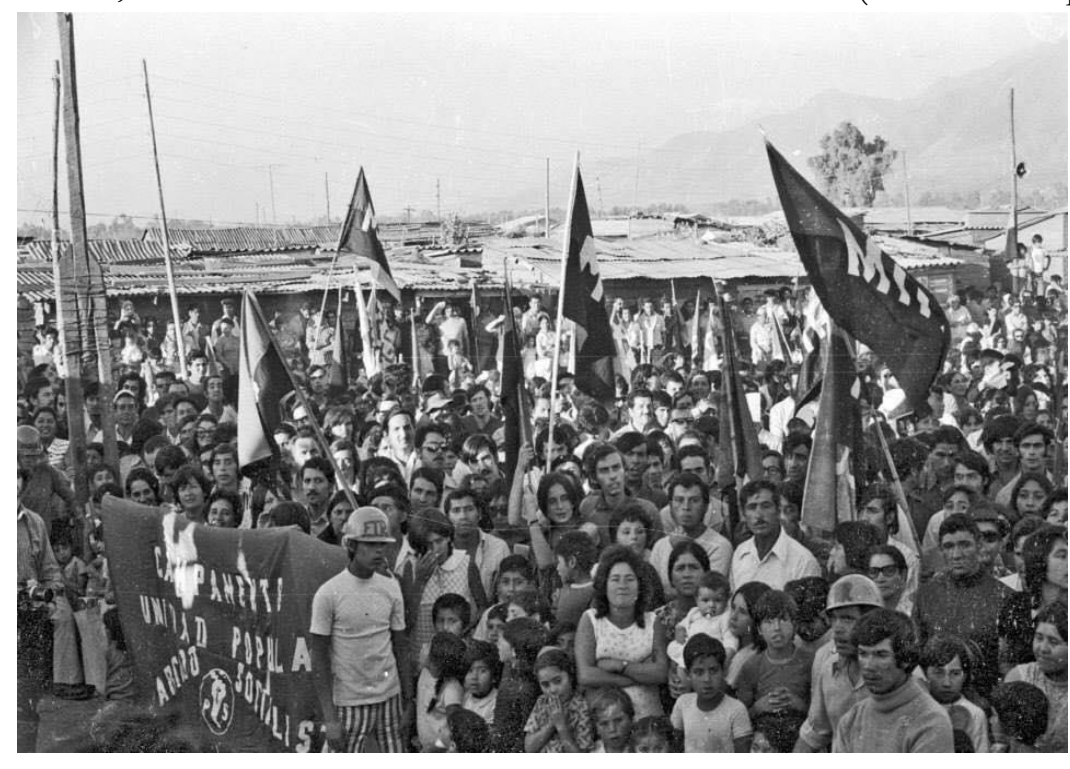
cita una entrevista que "una agencia de noticias" le había realizado a "algunos dirigentes del Comando de Sin Casa de Ñuñoa (bautizado como "Unidad Popular")"112: Alejandro Galán, "obrero textil, 22 años y Juan Godoy, 47 años, obrero metalúrgico". En ella, sostuvieron, respecto a la toma, que "de haber intervenido el Grupo Móvil no hubiéramos insistido. El Partido se opone a cualquier aventura.

Concentración de pobladores en lugar desconocido.

La consigna era no enfrentarnos a los 'pacos', y si nos querían sacar, que nos llevaran arrastrando. Prohibimos todo tipo de armas a los compañeros pobladores. Ni un cuchillo ni una piedra, para evitar las provocaciones"113.

En esta entrevista estos dirigentes se declaran, por primera vez dentro de las fuentes consultadas, como militantes políticos, refiriéndose con "el Partido" muy probablemente al PC, dadas las directrices que este señalaba, totalmente contrarias a cualquier tipo de lucha armada, la cual era la vía preconizada, sobre todo en ese entonces, por el MIR para que los pobladores, así como los trabajadores, lucharan por sus reivindicaciones. Además, el hecho de

112 Revista Punto Final, No 100, 17 marzo de 1970, 8-9.

${ }^{113}$ Idem. 
que exclusivamente políticos del PC hayan mediado entre la fuerza pública, primero, y las autoridades democratacristianas, después, con los pobladores, refuerza esta idea: antes, durante y después de la toma, el campamento Unidad Popular estaba dirigido por militantes comunistas. Sin embargo, esto no significa descartar que hayan existido liderazgos socialistas en su interior, así como sin militancia política: el mismo nombre que le dieron al campamento, idéntico al de la coalición electoral entonces formada por los partidos de izquierda tradicionales, de cierta manera demuestra la convergencia de fuerzas de izquierda que en su interior parece haber existido. Estos liderazgos pueden haber asumido cargos dirigentes una vez consolidado el campamento, lo que explicaría los dichos de Castells, que probablemente estaban basados en los resultados que los investigadores del CIDU obtuvieron con la aplicación de su encuesta, en 1971.

Las relaciones con el MIR, por su parte, más allá de la imagen anteriormente expuesta, no son muy claras. En el artículo anteriormente referido de la revista Punto Final se señalaba que "una conciencia solidaria y realmente unitaria despunta en las tomas de terrenos y otras batallas de los "sin casa", estén dirigidas por militantes comunistas, mapucistas, socialistas o miristas" "114, no viéndose en la práctica una división entre PC y MIR como la que algunos dirigentes propugnaban en esa época.

Sin embargo, antecedentes concretos de una movilización y organización conjunta no se encontraron en las fuentes consultadas. En la revista El Rebelde, asociada al MIR, por ejemplo, se reseñan ciertas acciones llevadas a cabo por pobladores del campamento Nueva La Habana en el sector, tales como una toma de la Municipalidad de La Florida, en 1971, o la formación -fallida- de un Consejo Comunal ese año ${ }^{115}$, pero no se menciona la participación en ellas del campamento Unidad Popular.

En 1972 se volvería a intentar formar un consejo comunal en la comuna, esto a partir de la formación de un comando comunal, denominado "San Rafael", el que aglutinaba a siete campamentos, entre los cuales, igualmente, no estaba el Unidad Popular ${ }^{116}$.

Así, parece ser que la línea política dominante en el campamento Unidad Popular fue, en principio, la representada por el PC, pero habría ido derivando hacia una conjunción entre ella y la que llevaba adelante el PS, más radicalizada y cercana al MIR, aunque sin llegar a ser mayoritaria. Esto puede haber llevado a un conflicto de liderazgos y direcciones al interior del campamento, el que, presumiblemente, los investigadores del CIDU caracterizaron en su artículo de 1972. Esa habría sido la situación cuando la crisis de abastecimiento azotó, sobre todo, a los pobres de la ciudad, cuando la "ofensiva contra la UP pasa a un nivel superior" al anteriormente mostrado: "la del enfrentamiento social y del boicot económico generalizados" $" 117$.

114 Idem.

115 Leiva, 2007, op. cit., 43.

116 Ibid., 160.

117 Gaudichaud, 2005, op. cit., 94. 


\section{La crisis de la Unidad Popular}

Cuando "comenzó la inflación, el mercado negro, los problemas surgieron rápidamente", constituyéndose una "Canasta" en el campamento, "donde se abastecían los pobladores" 118 , indicaba Andrés Moreno en 1989. Esta canasta, según Pastrana y Threlfall, correspondía a una serie de productos básicos que eran distribuidos "a través de Agencias Graham", una distribuidora estatal, "a los Almacenes del Pueblo, de localización permanente" 119 , para hacer frente a la crisis económica que comenzaba a sufrir el gobierno de la Unidad Popular. Por ello, lo que se constituyó en el campamento fue, probablemente, un Almacén del Pueblo. Según estos mismos autores, cabe señalar, uno de los primeros campamentos en adoptar dicho sistema de abastecimiento directo fue el Nueva La Habana.

Este sistema no habría funcionado del todo bien, sin embargo, en el campamento Unidad Popular, según aseguraban algunos informantes en 1989: "era un beneficio solo para algunos, para los demás no. Se repartían las cosas 'por debajo' según el dicho" ${ }^{\text {"120 }}$. Estas críticas a la dirigencia del campamento se repetían entre algunos pobladores que recordaban esta época ese año: mientras uno aseguraba que para una navidad "los delegados de la junta de vecinos pidieron dinero para los niños pero se corrieron con el billete"121, otro afirmaba que "había organización pero los dirigentes apoyaban para otro lado, empezaron a cobrar cuotas; como en toda organización había aprovechamiento de los más débiles"122.

El clima de inestabilidad política y social se haría sentir en el campamento: "La situación comenzó a ponerse inquietante pues no se sabía que podía pasar. En la población comienzan a faltar los alimentos básicos" ${ }^{123}$. Lo más inquietante era el rumor de que se tomarían las casas que en la población se construían para los habitantes del campamento. Según señalaba una pobladora "algunas casas se entregaron y otras fueron tomadas", incluso "antes de que mataran a Allende" 124 , tanto por personas ajenas al campamento como por pobladores de este que no tenían claridad sobre su futuro habitacional.

\section{E1 golpe de Estado}

Cuando se veía próximo el golpe de Estado, la "canasta" fue quemada: "se corría la voz de quienes habían sido, habían tirado una botella con parafina. Dijeron que repartirían la mercadería para el 11, pero no se pudo porque hubo allanamiento" ${ }^{125}$. Mismo destino corrieron todo tipo de documentos relacionados con la Unidad Popular y los partidos que la formaban: "mientras se oía el último discurso de Salvador Allende, en los pozos sépticos se perdían los documentos que podían implicar a alguna organización"126.

\footnotetext{
118 Moreno, 1990, op. cit., 51.

119 Pastrana y Threlfall, 1974, op. cit.

${ }^{120}$ Moreno, 1990, op. cit., 51.

${ }^{121}$ Ibid, 50.

122 Ibid, 51.

123 Ibid, 54.

${ }^{124}$ Idem.

125 Moreno, 1990, op. cit., 51.

126 Ibid, 55.
} 
Tras el golpe de Estado, la Dra. Laura Elena Gálvez, el jueves 13 de septiembre específicamente, "partió a la población Unidad Popular y por varios días, ayudó a repartir en ambos sectores lo que los pobladores bautizaron tristemente como el 'último regalo del Presidente Allende': un camión repleto de pañales"127.

\section{Conclusiones}

Para concluir esta investigación se comenzará enjuiciando la hipótesis que se planteó en un comienzo, la cual era que el campamento Unidad Popular sí se insertó en el movimiento de pobladores desarrollado entre 1970 y 1973, y que en su interior sí se dieron formas organizativas y de lucha que podrían considerarse similares a otras desarrolladas en esa época, y que han sido consideradas como manifestaciones de un poder popular embrionario surgido a partir de la movilización llevada a cabo por los pobladores.

En cuanto a la primera parte de esta hipótesis, se sostiene, primero, y tal como se señaló en la discusión conceptual, que el movimiento de pobladores fue un movimiento social, y que el campamento estudiado efectivamente se insertó en él, recurriendo a un antiguo repertorio de acción y organización que consolidaron los pobladores que dieron forma a la población La Victoria, en 1957. Este se caracterizó por la combinación de la acción directa e ilegal, sobre todo plasmada en su estrategia de movilización por excelencia, la toma de terrenos, y la acción institucional, mediada a través de partidos políticos y la iglesia católica. En el caso del campamento Unidad Popular, se verificó una mediación realizada particularmente por políticos del PC, la cual fue exitosa ya que facilitaría el asentamiento de los pobladores en el terreno ocupado, primero, y la construcción de una población para ellos en el mismo lugar, después.

La segunda parte de la hipótesis es más complejo aceptarla o rechazarla categóricamente, ya que ello supone concebir el poder popular de una u otra manera: de manera clásica, como un poder alternativo al poder estatal que busca derrotar a este último a través de una revolución violenta, o bien como un poder autónomo al poder estatal que, sin embargo, no tiene como condición de existencia su oposición a este, sino que puede complementarlo, o bien "socializarlo" desde "abajo", desde las bases de la sociedad.

En el primer caso, habría de rechazarse la hipótesis, y sostenerse que solo los campamentos liderados por el MIR y su política "rupturista" de acción desarrollaron un poder popular "embionario y consciente", que se planteó desde un comienzo como en oposición al poder desplegado por el Estado burgués y sus instituciones (con las que, sin embargo, tuvo que negociar y convivir una vez que la izquierda asumió el gobierno). En el campamento Unidad Popular no se pensó jamás desarrollar un poder opuesto al Estado: primero se organizó en oposición al gobierno, mas no al Estado, para luego relacionarse con este a través del mismo aparato gubernamental, con el cual se dieron relaciones asistencialistas, pero también acciones reivindicativas.

Concibiendo el poder popular de una manera más amplia, como un poder autónomo al estatal, sin embargo, sí se aceptaría la hipótesis, ya que se habrían dado formas organizativas y

${ }^{127}$ Bonnefoy Miralles, 2005, op. cit., 57. 
de participación que pueden considerarse como experiencias de democracia directa, a decir de Mario Garcés, tales como comités y comandos de los sin casa, comisiones de vigilancia, de salud, etc. Estas formas organizativas no se crearon en este campamento, siendo fruto de un largo desarrollo del movimiento de pobladores y sus organizaciones. Quienes las vieron como novedad a principios de los 70, en los campamentos asociados al MIR, como Manuel Castells y los pioneros estudios del CIDU, así como Enrique Pastrana y Mónica Threlfall, desconocieron ese bagaje, lo que repercutió negativamente en caracterizaciones posteriores que se hicieron del movimiento poblacional y los campamentos, al desconocerse la influencia que la izquierda tradicional, o gradualista, tuvo tempranamente en su desarrollo como movimiento político ${ }^{128}$.

En el caso de la presente investigación, se concibe el poder popular como un proceso de "democratización/socialización del poder político" ${ }^{129}$ por lo que la segunda parte de la hipótesis inicial también se acepta.

Aceptar la hipótesis, empero, no implica sostener que los pobladores del campamento Unidad Popular, y quienes se tomaron terrenos para reivindicar su lugar en la ciudad antes que ellos, no estuvieran asociados a una corriente política institucionalizada. Se reconoce la importancia que tuvieron los partidos de izquierda, sobre todo el PC, en el desarrollo del movimiento de pobladores y sus modos de acción y organización, a partir de los cuales pudo desplegar formas embrionarias de poder popular, las que alcanzaron su mayor grado de desarrollo durante la Unidad Popular, en parte fomentadas por la irrupción del MIR en el movimiento, sin duda.

No se pretende sostener, sí, que la importancia de los partidos políticos estuviese dada por la injerencia de los políticos "profesionales" en el movimiento de pobladores, a través de sus mediaciones y relaciones, sino que por la cultura política que los pobladores-militantes habían forjado tras décadas de desarrollo. Así, por ejemplo, se destaca el hecho de que los dirigentes que planificaron la toma que dio origen al campamento Unidad Popular fueron dirigentes comunistas, no solo dirigentes sociales, los que cargaban con una ideología, una práctica y un apoyo organizativo que les ayudaría a llevar a cabo la acción.

No se puede, pues, obviar la relación existente entre las organizaciones políticas y la experiencia histórica de los campamentos chilenos. Las divergencias políticas al interior del campamento estudiado, de hecho, parecen haber tenido un efecto negativo en su desarrollo, en un conflicto social que no se pudo resolver, agudizado por la crisis económica y política que atravesaba la Unidad Popular en sus últimos meses.

Así, en definitiva, se plantea que lo social y lo político, entendido como el campo de lucha de lo público, no tienen por qué analizarse separadamente, pues en la realidad, como lo comprueba esta investigación, están más cerca de lo que muchas veces se piensa. La política, "como fetichización de "lo político" respecto de "lo social""130 puede re-socializarse, democratizarse, tal como lo vio Salvador Allende. No necesariamente, sí, desde arriba, "desde

\footnotetext{
${ }^{128}$ Esa mirada un tanto despreciativa de la acción colectiva poblacional en tanto estuviera ligada a partidos de la izquierda tradicional, y ensalzadora de aquella ligada al MIR, tuvo probablemente su origen, siguiendo a Espinoza, 1998, op. cit. 79, más que nada en las "expectativas de los investigadores y los intelectuales que, influidos por el clima ideológico de esos años, querían ver en los pobladores los agentes de un cambio radical".

${ }^{129}$ Cancino, 1988, op. cit., 335.

${ }^{130}$ Mónica Iglesias V. "Lo social y lo político en Chile: itinerario de un desencuentro teórico y práctico", Izquierdas, $\mathrm{N}^{\circ}$ 22, Santiago, 2015, 246.
} 
el Estado (...) para producir una desconcentración del poder", sino que, desde abajo, politizándose lo social. Esta ruta, según Mónica Iglesias, "fue formulada históricamente como "poder popular"” 131 y es la que los pobladores del campamento Unidad Popular, entre otros, intentaron transitar.

Con el estudio del campamento Unidad Popular se intentó dar luces sobre las relaciones que se establecieron entre el movimiento de pobladores y la política, tanto institucional como popular, entre los álgidos años 1970 y 1973. Esto para explorar las formas de poder popular que se desarrollaron en los campamentos de esa época, más allá de las que se han estudiado respecto al campamento Nueva La Habana. Si bien este fue sin duda paradigmático, ha eclipsado el estudio de otros campamentos que en ese entonces existieron, cuyas experiencias de formación y organización pueden permitir una comprensión más acabada del ciertamente complejo movimiento de pobladores que se desarrolló en esos años.

Como punto de partida pueden cuestionarse las conceptualizaciones que en la década del 70 dividieron dicho movimiento en tres modelos organizativo-políticos, vinculados al PDC, el PC y el MIR, resaltándose la cualidad revolucionaria de este último. El campamento Unidad Popular, vinculado generalmente al PC, según este esquema se habría ligado de manera subordinada y pasiva con el gobierno de la Unidad Popular. Sin embargo, como se vio, en su seno parece haber tenido un liderazgo conjunto PC-PS, y también acercamientos con el MIR, así como ciertas demostraciones de acción directa como medidas de presión contra el gobierno. Estas relaciones demuestran lo complejo que fue su desarrollo, y que reducir su comprensión a su correspondencia con un modelo estratégico "estandarizado" es limitante y problemático. Analizarlo sin esperar que se amolde a cierto modelo podría permitir entender algunas de sus aparentemente contradictorias características, así como, de manera más general, repensar lo que se entiende por poder popular.

Siendo uno de los campamentos más grandes de su época (el más grande, de hecho, según Manuel Castells ${ }^{132}$, no extrañan del todo los conflictos que se dieron en su interior. El estudio de su experiencia puede ser útil, además, a la hora de pensar en cómo superar situaciones de conflicto al interior de asentamientos, organizaciones o movimientos sociales.

Esa y muchas otras líneas de investigación se pueden abrir a partir del presente trabajo, solo considerando la experiencia del campamento Unidad Popular. Por ejemplo cinfluyó en su desarrollo su cercanía con el campamento Nueva La Habana? ¿Qué tanta relevancia tuvo la militancia comunista en su dirigencia? ¿Cómo llegó a darse el liderazgo conjunto entre comunistas y socialistas, y qué características tuvo esta relación en la organización y desarrollo del campamento? ¿Qué tan identificados con los proyectos políticos de izquierda estaban sus habitantes? ¿Cuánta influencia tuvo en su origen la Federación Provincial de Pobladores, a la cual el Comando de los Sin Casa de Nuñoa estaba afiliado? Ahora bien, también pueden hacerse estas, y otras interrogantes, respecto a otros campamentos existentes en ese entonces, el estudio de los cuales puede ser tan o más útil a la hora de pensar el movimiento de pobladores, y la relación de lo social con lo político.

Respecto a las fuentes bibliográficas de información existentes sobre el campamento estudiado, al menos, son muy escasas. La revisión de fuentes primarias, a su vez, tales como

\footnotetext{
${ }^{131}$ Idem.

132 Castells, 1983, op. cit., 201.
} 
periódicos y revistas de la época, es compleja dado el desconocimiento de fechas exactas en que pueden encontrarse referencias a él en ellas. Así, por ejemplo, resultó sencillo buscar información sobre la toma de terreno, ya que se tenía claridad sobre la fecha en que se había realizado (11 de enero de 1970), mas no se contaba con la misma claridad respecto a otro hecho del que hubiese sido muy interesante tener más referencias: la visita de Salvador Allende, como candidato presidencial, al campamento. En cuanto a otras referencias en prensa, que no traten sobre un hecho tan puntual, son aún más difíciles de encontrar.

Por tanto, resulta fundamental, si se quiere avanzar en los conocimientos que se tienen sobre este campamento, investigarlo utilizando las técnicas de la historia oral. El hecho de que aún viven protagonistas de su historia debe ser aprovechado, antes de que sea demasiado tarde. Un escrito que en 1989 se valió de estas técnicas para investigar su historia resultó de una relevancia fundamental para este estudio. Sin embargo, la época en que fue desarrollado dificultó que en él se recogieran testimonios más precisos sobre las relaciones que se dieron entre las organizaciones políticas y el campamento, tal como declaraba su autor en su inicio: "la gente que en su mayoría participó en este gran acontecimiento, está sumisa sin querer participar en esta pequeña recopilación histórica, e incluso algunos de sus dirigentes en aquel entonces, se han negado a cooperar" ${ }^{\text {"133 }}$.

Es de esperar que dicha negativa haya cambiado en la actualidad, y que se pueda profundizar en la relación que en él se dio entre política y pobladores a partir de las memorias de quienes, hace casi medio siglo, se movilizaron y se hicieron eco en la ciudad, llevando a cabo la primera toma de terrenos del trascendental año 1970.

\section{Referencias bibliográficas}

\section{Libros}

Bonnefoy Miralles, Pascale. Terrorismo de Estadio. Prisioneros de guerra en un campo de deportes, Santiago, CESOC, 2005.

Cancino, Hugo. La problemática del poder popular en el proceso de la vía chilena al socialismo 1970-1973, Aarhus, Aarhus University Press, 1988.

Castells, Manuel. The city and the grassroots: a cross-cultural theory of urban social movements, Berkeley, University of California Press, 1983.

Cofré, Boris. Campamento Nueva La Habana, el Mir y el Movimiento de Pobladores, 1970-1973, Concepción, Escaparate, 2007.

Gaudichaud, Frank. Poder popular y cordones industriales. Testimonios sobre el movimiento popular urbano, 1970 1973, Santiago, LOM, 2004.

Pastrana, Ernesto y Threlfall, Mónica. Pan, techo y poder: el movimiento de pobladores en Chile (1970-1973), 1974, Disponible en internet: http://www.blest.eu/biblio/pastrana/index.html

133 Moreno, 1990, op. cit., 40. 


\section{Capítulos de libros}

Cáceres, Gonzalo. "Santiago de Chile. La capital de la izquierda", en Adrián Gorelik y Fernanda Arêas Peixoto (eds.), Ciudades sudamericanas como arenas culturales, Buenos Aires, Siglo Veintiuno, 385-402.

Duque, Joaquín y Pastrana, Ernesto. "La movilización reivindicativa urbana de los sectores populares en Chile: 1964-1972", en Alfredo Rodríguez y Paula Rodríguez (eds.), Santiago, una ciudad neoliberal, Quito, Organización Latinoamericana y del Caribe de Centros Histórico, 2009, 53-64.

Garcés, Mario. "Las tomas en la formación de Santiago", en Nosotros los chilenos 5: el mundo de las poblaciones, Santiago, LOM, 2004, 4-33.

Garcés, Mario. "Construyendo "poblaciones", en Julio Pinto (ed.), Cuando bicimos historia. La experiencia de la Unidad Popular, Santiago, LOM, 2005, 57-79.

Garcés, Mario. "Los años de la Unidad Popular: cuando los pobladores recreaban las ciudades chilenas", en Julio Pinto (ed.), Fiesta y drama. Nuevas historias de la Unidad Popular, Santiago, LOM, 2014, 51-73.

Gaudichaud, Frank. "Construyendo "poder popular": el movimiento sindical, la CUT y las luchas obreras en el periodo de la Unidad Popular", en Julio Pinto (ed.), Cuando bicimos historia. La experiencia de la Unidad Popular, Santiago, LOM, 2005, 81-105.

Moreno, Andrés. "Campamento Unidad Popular (Villa Los Copihues)”, en Hanny Suckel (ed.), Historias Locales I, Santiago, Jundep, 1990, 37-59.

Pinto, Julio. "Hacer la revolución en Chile", en Julio Pinto (ed.), Cuando bicimos historia. La experiencia de la Unidad Popular, Santiago, LOM, 2005, 9-33.

\section{Artículos}

Álvarez Vallejos, Rolando. "La Unidad Popular y las elecciones presidenciales de 1970 en Chile: la batalla electoral como vía revolucionaria", Osal, N²8, Año XI, Buenos Aires, 2010, 219-239.

Aravena Núñez, Pablo. "Patrimonio, historiografía y memoria social: "presentismo radical" y abdicación de la operación histórica", Diálogo Andino, N 45, Arica, 2014, 77-84.

Castells, Manuel. "Movimiento de pobladores y lucha de clases en Chile", EURE, $\mathrm{N}^{\circ}$ 7, vol. 7, Santiago, 1973, 9-35.

Cofré, Boris. "Pensar la historia desde los movimientos sociales urbanos en Chile: los pobladores del Gran Santiago", Boletín de Geografía, N 30, 2009, 31-41.

Cofré, Boris. "El movimiento de pobladores en el Gran Santiago: las tomas de sitios y organizaciones en los campamentos. 1970-1973", Tiempo Histórico, N 2, Santiago, 2011, 133-157.

Cortés, Alexis. Los comunistas y la toma de terrenos de La Victoria. A 50 años de una de las tomas más grandes de Latinoamérica, 2007, disponible en internet:

http://www.generacion80.cl/documentos/docs/Los_Comunistas Toma La Victoria.pdf

Cortés, Alexis. "El movimiento de pobladores chilenos y la población La Victoria: ejemplaridad, movimientos sociales y el derecho a la ciudad", EURE, No 119, vol. 40, Santiago, 2014, 239-260.

Equipo de Estudios Poblacionales CIDU, "Reivindicación urbana y lucha política: los campamentos de pobladores en Santiago de Chile", EURE, N 6, vol. 2, Santiago, 1972, 55-82.

Espinoza, Vicente. "Historia social de la acción colectiva urbana: los pobladores de Santiago, 19571987”, EURE, No 72, vol. 24, Santiago, 1998, 71-84.

Fiori, Jorge. "Campamento Nueva La Habana: estudio de una experiencia de autoadministración de justicia”, EURE, N ${ }^{\circ}$ 7, vol. 3, Santiago, 1973, 83-101.

Garcés, Mario. La revolución de los pobladores, treinta años después..., 2003, disponible en internet: http://www.ongeco.cl/wp-content/uploads/2015/04/La_revolucion de los_pobladores.pdf 
Iglesias Vásquez, Mónica. "Lo social y lo político en Chile: itinerario de un desencuentro teórico y práctico", Izquierdas, N 22, Santiago, 2015, 227-250.

Leiva, Sebastián. "De la toma de terrenos a la toma del poder": el campamento "Nueva La Habana" y una nueva óptica para la movilización poblacional", Revista de Historia Social y de las Mentalidades, N$^{\circ}$ 6, Santiago, 2002, 109-123.

Raschke, Joachim. "Sobre el concepto de movimiento social", Zona Abierta, N 69, Madrid, 1994, 121 134.

Revista Docencia. La educación hace treinta años: vivencias de diversos actores, 2003, disponible en Internet: http://www.revistadocencia.cl/new/wp-content/pdf/20100730003400.pdf

Rojas Flores, Jorge. "La lucha por la vivienda en tiempos de González Videla: las experiencias de las poblaciones Los Nogales, Lo Zañartú y Luis Emilio Recabarren en Santiago de Chile, 1946-1947”, Izquierdas, $\mathrm{N}^{\circ}$ 39, Santiago, 2018, 1-33.

\section{Tesis}

Leiva, Sebastián. "Teoría y práctica del poder popular: los casos del Movimiento de Izquierda Revolucionaria (MIR, Chile, 1970-1973) y el Partido Revolucionario de los Trabajadores - Ejército Revolucionario del Pueblo (PRT-ERP, Argentina, 1973-1976)", Tesis para optar al grado de Magíster en Historia, mención Historia de América, Universidad de Santiago de Chile, 2007. 